\title{
Tecnociencias de la información y participación ciudadana
}

\author{
JAVIER ECHEVERRÍA EZPONDA \\ Instituto de Filosofía, CSIC
}

RESUMEN. Las tecnologías de la información y la comunicación (TIC) deben ser consideradas como componentes de un nuevo sistema tecnológico que transforma e incrementa las capacidades de acción de los seres humanos, incluyendo las capacidades de participación ciudadana. Se distinguen dos modos de participación: pasivos (radio, televisión) y activos (Internet, videojuegos, tecnologías multimedia). Tras analizar diversos ejemplos de participación activa con ayuda de las TIC (voto electrónico, asociacionismo, manifestaciones virtuales, cooperativismo electrónico, deportes y juegos electrónicos, etc.), se concluye que todas ellas se producen en un nuevo espacio social, el tercer entorno o espacio electrónico, que tiene una estructura específica y en el que ha surgido una nueva forma de poder: los Señores del Aire (o Señores de las Redes), es decir, las empresas transnacionales que controlan el acceso y el funcionamiento del espacio electrónico. Para promover la participación ciudadana habría que democratizar ese nuevo espacio social, logrando que los usuarios de las TIC sean considerados como ciudadanos de dicho espacio electrónico y transnacional, no sólo como consumidores de productos electrónicos en un gran telemercado global.
ABSTRACT. Information and communication technologies (ICT) must be viewed as components of a new technological system which transforms and increases human capabilities for action, including capabilities for citizens' participation. Two types of participation are distinguished: passives (radio, television) and actives (Internet, videogames, multimedia technologies). After analysing several examples of active participation with the aid of ICT (electronic vote, associacionism, virtual demonstrations, technological cooperativism, electronic games and sports, etc.), we conclude that the technological system ICT produces a new social domain, the third environnement or electronic domain. It has its own especific structure and contributes to the emergence of a new form of power: the Lords of the Air or Lords of the Networks, that is, the transnational enterprises wich control the access and the functionning of the electronic domain. To promove citizens' participation in the new electronic domain, it should be democratized, so that users of ICT would be considered as citizens of this electronic and transnational domain, not only as consumers of electronic goods within a great global telemarket. 


\section{Introducción}

En este artículo partiremos de tres grandes hipótesis, previamente desarrolladas en anteriores publicaciones ${ }^{1}$ :

a) A lo largo del siglo $\mathrm{Xx}$ ha surgido una nueva modalidad de ciencia, la tecnociencia, que integra en una empresa común a científicos, técnicos, ingenieros, inversores, gestores, empresarios, políticos, juristas y, en numerosas ocasiones, también a instituciones militares. Las tecnociencias transforman radicalmente el mundo, y en particular las sociedades, llegando a constituir una nueva modalidad de poder, cuyo predominio se ha manifestado claramente en el caso de las guerras de fin de siglo (Golfo Pérsico, Kosovo, Afganistán, Irak). Las tecnociencias también han incidido profundamente en la actividad empresarial, comercial, cultural, sanitaria, educativa y de entretenimiento, por lo que cabe hablar de la revolución tecnocientífica del siglo XX. Dicha revolución no altera tanto los paradigmas del conocimiento (Kuhn, 1975, 1989) cuanto la estructura de la práctica tecnocientífica. Los objetivos de los grandes proyectos tecnocientíficos no son sólo epistémicos o técnicos, sino también empresariales, financieros, políticos o militares. En algunos casos se promueven acciones tecnocientíficas de interés social (sanidad, medio ambiente), pero incluso en esas ocasiones los objetivos son mixtos, puesto que la nueva modalidad de ciencia se organiza como empresa, pública o privada. Las comunidades de científicos e ingenieros quedan subordinadas a entidades más complejas, a las que cabe denominar agencias tecnocientíficas (Pickering, 1995). La investigación científica experimenta profundos cambios en su estructura, al igual que la difusión ulterior de los resultados, frecuentemente mediatizada por un mercado donde compiten distintas empresas e instituciones tecnocientíficas.

Las nuevas tecnologías de la información y la comunicación desempeñan un papel fundamental en esta transformación de la actividad científico-tecnológica, así como de la vida social. Por ello hay que prestarles una atención prioritaria. Además generan nuevas formas de participación ciudadana (comunidades virtuales, grupos de debate en Internet, divulgación de la ciencia por televisión, etc.), que conviene estudiar con detalle. Algunas de esas tecnologías tienen alto grado de aceptación social, otras suscitan reticencias y desconfianza. La actitud de las diversas sociedades ante las tecnociencias es muy distinta a la que mostraron las sociedades europeas en relación a la ciencia o la ingeniería durante la revolución industrial. La

\footnotetext{
1 Ante todo en J. Echeverría, 1999 y 2003, siguiendo una línea de investigación que ha sido financiada por el Ministerio de Ciencia y Tecnología (Proyectos PB 98-0495-C08-01 y BFF200204454-C10-01) y desarrollada en el Instituto de Filosofía del CSIC, en colaboración con las Unidades Asociadas del CSIC y las Universidades del País Vasco y Sevilla.
} 
emergencia de la sociedad de la información y el conocimiento es concomitante a la revolución tecnocientífica y por ello las relaciones entre las tecnociencias y la sociedad se producen ante todo en el marco de la sociedad de la información. No se niegan los grandes avances científicos y tecnológicos, pero sí se ponen en cuestión los valores e intereses que guían la actividad tecnocientífica. El amplio movimiento contra la militarización de la ciencia que se suscitó en los Estados Unidos durante la década 1960-1970 supuso la primera gran crisis de la macrociencia (Big Science), que alcanzó a otros muchos países avanzados (mayo de 1968). Desde entonces, el control social de la ciencia y la participación ciudadana en los procesos de toma de decisiones son cuestiones que suscitan profundos debates. Los conflictos de valores son estructurales en las tecnociencias, puesto que los valores sociales y democráticos se contraponen muy frecuentemente a los valores de los cinco grandes agentes de las empresas tecnocientíficas: científicos, tecnólogos, empresarios, políticos y militares.

b) Las nuevas tecnologías de la información y la comunicación tienen orígenes diferentes $\mathrm{y}$, hasta hace poco, han sido estudiadas por separado. Para analizar su impacto social y las nuevas modalidades de participación ciudadana que generan es preciso cambiar de perspectiva y considerarlas conjuntamente. Partimos de la hipótesis de que su progresiva convergencia ha generado un sistema tecnológico, al que llamaremos sistema TIC. En lugar de pensar que por una parte está el teléfono, por otra la radio y la televisión, luego las redes telemáticas tipo Internet y las redes bancarias de dinero electrónico y, por último, las tecnologías multimedia, los videojuegos y la realidad virtual, diremos que esas ocho tecnologías, junto con los satélites de telecomunicaciones y las redes eléctricas, convergen en un sistema tecnológico cada vez más integrado ${ }^{2}$. Aparte de las transformaciones que ha producido en relación al acceso, tratamiento y almacenamiento de la información y de los tremendos cambios habidos en la comunicación a distancia entre seres humanos y artefactos tecnológicos, el sistema TIC ha abierto nuevas posibilidades para la acción, la producción, la distribución, el intercambio y el consumo de bienes, sean éstos económicos o de otro tipo, incluidos importantes bienes sociales, como el conocimiento. Por su impacto social, el sistema TIC es comparable al sistema industrial. La emergente sociedad de la información no sería posible sin esa progresiva constitución y desarrollo de un nuevo sistema tecnológico, que ha tenido lugar en el último cuarto del siglo XX.

En la historia de la tecnología ha habido muchos sistemas tecnológicos: agrarios, de pesca, mineros, militares, industriales, etc. En este artículo no

${ }^{2}$ Se trata de un sistema abierto, al que se incorporan innovaciones tecnológicas continuamente, que pasan a ser periféricas de las iniciales. Esa integración progresiva de diferentes artefactos es signo del carácter sistémico que van tomando las nuevas tecnologías de información y comunicación, como se les denomina habitualmente. 
analizaremos a fondo esa noción, que es central en filosofía de la tecnología $^{3}$, sino que nos limitaremos a señalar que un sistema tecnológico modifica profundamente las capacidades de acción de los seres humanos, y en algunos casos transforma radicalmente la vida social, al soportar nuevas formas de interrelación social. Éste es el caso del sistema TIC, el cual abre la posibilidad de actuar a distancia y en red, así como de recibir a distancia los resultados y efectos de las acciones que otros realizan. Una acción televisada o un mensaje radiofónico impactan en la mente de millones de personas, abriendo nuevos canales para la información, el entretenimiento y la participación. Una acción así produce efectos directos, pero a distancia. Por ello algunas de las tecnologías TIC (radio, televisión) se convirtieron desde el principio en un instrumento de poder. El sistema TIC posibilita un nuevo tipo de acción, las multiacciones a distancia, y por eso constituye un sistema tecnológico que transforma radicalmente las sociedades en las que se implanta. Las personas que usan competentemente los aparatos básicos del sistema TIC (teléfono, mando a distancia, ordenador, tarjetas de débito y crédito, CD-Rom, DVD, consola de videojuegos, Webcam, videocámara, organizador personal, MP3, etc.) pueden interactuar entre sí aunque estén a distancia, siempre que estén interconectados a través de redes telemáticas. Muchas de esas acciones son informacionales y comunicacionales, pero no todas. Enviar un virus a través de Internet, telecontrolar un robot, un avión o un misil, invertir en bolsa desde un cajero automático, jugar en red, teletrabajar, componer o interpretar música electrónica, diseñar en red un edificio, hacer un experimento en una estación espacial o llevar a cabo una teleoperación médica son ejemplos de diversos tipos de acciones que pueden ser llevadas a cabo gracias a algunas tecnologías TIC y que no son acciones comunicativas o informativas, aunque requieran instrumentos informacionales y comunicacionales. Por decirlo en términos de Amartya Sen ${ }^{4}$, el sistema TIC transforma el espacio de capacidades de acción de los seres humanos, tanto individualmente como en grupo. A diferencia de otros sistemas tecnológi$\cos$, que fueron construidos para controlar y dominar la naturaleza, el sistema TIC transforma ante todo las sociedades, hasta el punto de que abre la vía hacia una nueva modalidad de sociedad, la sociedad de la información y el conocimiento. Partiendo de esta segunda hipótesis, no es de extrañar que las relaciones entre la sociedad y esta modalidad de tecnociencia hayan cambiado. En muchas ocasiones se suscitan auténticos conflictos de valores entre los agentes sociales (ONGs, asociaciones de usuarios y consumidores, etc.) y los agentes tecnocientíficos.

c) ¿Cómo sucede todo esto? Gracias a la construcción de un nuevo espacio social, el espacio electrónico, también denominado espacio de flujos

${ }^{3}$ Veáse, por ejemplo, M. A. Quintanilla, Tecnología: un enfoque filosófico, Madrid, Fundesco, 1989.

${ }_{4}^{4}$ A. Sen, Bienestar, justicia y mercado, Barcelona, Paidós, 1997. 
por Manuel Castells ${ }^{5}$ o tercer entorno por quien esto escribe ${ }^{6}$. No es un espacio geográfico ni urbano, aunque se superponga a las ciudades, los países y las regiones. Su estructura es reticular, no territorial ${ }^{7}$. Sin embargo, en la medida en que un país o una región desarrolle su espacio electrónico, la sociedad de la información también se desarrollará en ese país. De lo contrario, será una sociedad informacionalmente subdesarrollada. Conforme a la concepción sistémica de las tecnologías antes aludida, diremos que el espacio electrónico es una propiedad emergente del sistema TIC. Aunque en su origen las TIC sean tecnologías de información y comunicación, su evolución y su progresiva convergencia ha generado un nuevo espacio para la acción social, el tercer entorno ${ }^{8}$, donde son posibles todo tipo de acciones sociales, incluida la participación ciudadana. El espacio electrónico no se reduce a Internet, aunque la red sea uno de sus ámbitos más relevantes para el desarrollo de una sociedad civil de la información. Cuando un niño está ante una pantalla de videojuegos o cuando una persona está operando con un fichero en su ordenador o viendo una grabación familiar en el televisor, están en el espacio electrónico privado, que no debe ser confundido con los ámbitos públicos del tercer entorno.

El espacio electrónico interactivo (redes telemáticas) fue desarrollado en primer lugar por militares, financieros y científicos. Paralelamente, la televisión y la radio generaron nuevas formas de información, entretenimiento y publicidad, transformando por completo la relación entre políticos y ciudadanos. La convergencia paulatina entre esos dos grandes ámbitos del tercer entorno, posibilitada por la digitalización de la radio, la televisión y la información, permitió en la década de los noventa la expansión y consolidación del nuevo espacio social. El espacio electrónico fue expandiéndose por diversos países (empezando por los Estados Unidos, Europa, Japón, Canadá y el Primer Mundo), por distintos sectores sociales (empresas TIC, comercio electrónico, prensa digital, libros y música electrónica, telemedicina, e-educación, e-administración, arte electrónico, etc.) y, finalmente, está llegando a las familias y a las casas. En los países informacionalmente desarrollados, el número de personas conectados a las redes interactivas (telefónicas, telemáticas) crece continuamente, incrementando el número potencial de $e$-ciudadanos. El tercer entorno no sólo se superpone al planeta, a los países y a las ciudades, sino que también recubre nuestras casas y

\footnotetext{
5 M. Castells, La Era de la Información, 3 vols, Madrid, Alianza, 1997-1999.

6 J. Echeverría, Los Señores del Aire. Telépolis y el Tercer Entorno, Barcelona, Destino, 1999.

7 Para un estudio a fondo de la estructura del espacio electrónico, veáse Echeverría, 1999, op. cit., cap. I.

${ }^{8}$ El primer entorno es la naturaleza (physis), el segundo es la ciudad y el Estado (pólis), el tercero es el espacio electrónico, es decir, el entramado de redes telefónicas, televisivas, telemáticas, etc. a través de las cuales fluyen las informaciones y comunicaciones generadas por el sistema TIC.
} 
oficinas. Frente a la pasividad inicial de la ciudadanía, reducida a la condición de radioyentes y telespectadores, el nivel de actividad de las personas en el espacio electrónico crece sin parar, al igual que sus capacidades de acción en el tercer entorno.

La característica más notable del nuevo espacio social estriba en desbordar las fronteras territoriales, poniendo en cuestión la primacía de los Estados-nación y de los Mercados-nación. Las empresas transnacionales que dominan y promueven el sistema TIC (los Señores del Aire) son los agentes sociales más relevantes en el nuevo espacio social, produciéndose una profunda transformación de las relaciones de poder económico y militar. La lucha por el poder en el tercer entorno es una de las grandes peculiaridades de nuestro tiempo. Paralelamente, surgen movimientos sociales que actúan ante todo en el nuevo espacio social. El poder informacional ( $e$-poder) de los Señores del Aire es muy considerable ${ }^{9}$, pero los usuarios del sistema TIC van tomando conciencia de que pueden llegar a ser ciudadanos en el nuevo espacio social, no solamente consumidores o clientes. La constitución de una sociedad civil de la información en el espacio electrónico es el principal desafío por lo que respecta al sistema TIC. De ahí la importancia que tienen las diversas formas de participación ciudadana en el espacio electrónico, de las que vamos a ocuparnos a continuación.

\section{Participación activa y pasiva en el espacio electrónico}

Algunas tecnologías de la información (radio, televisión) han generado formas de participación ciudadana que han de ser consideradas como pasivas, debido a que los radioescuchas y los televidentes se han limitado a ser receptores de mensajes e imágenes, sin llegar a emitir sus propios mensajes en el propio espacio electrónico, por muy críticos que puedan ser respecto a los media en sus tradicionales escenarios domésticos, rurales y urbanos. Rotos los monopolios estatales de medios de comunicación, el telepúblico ha podido elegir entre diversas emisoras y cadenas, pero ha seguido sin poder intervenir activamente en los propios medios, a no ser por vías indirectas (llamadas telefónicas, cartas, asociaciones de usuarios, protestas, rechazo en el mercado de los productos publicitados, repudio social de determinados personajes y comportamientos televisivos o radiofónicos, etc.). Los ciudadanos han mantenido su espíritu crítico, pero éste no suele manifestarse en los propios medios, salvo en ocasiones especiales. Este tipo de usuarios del sistema TIC, la mayoría, son consumidores de información y de contenidos, paradigma que sigue vigente hoy en día, aunque en paulatino retroceso. Aparte de medios de información y entretenimiento, la radio y la televisión han sido

${ }^{9}$ Véase Echeverría 1999, op. cit., cap. III, para una explicación más amplia de la nueva modalidad de poder que detentan los Señores del Aire (o Señores de las Redes). 
ante todo medios de propaganda, tanto política como comercial, empresarial, institucional y social ${ }^{10}$. No en vano se han financiado mayoritariamente gracias a la publicidad. Sin embargo, incluso en los ámbitos generados por las TIC pro-pasivas han surgido tendencias hacia la ciudadanía. Ante todo, los televidentes aspiran a salir en televisión, es decir, a devenir ciudadanos, en lugar de reducirse a simples consumidores de información, publicidad y entretenimiento. Se trata de un movimiento social difuso, pero no por ello menos importante.

Otras tecnologías del sistema TIC han posibilitado una actitud mucho más activa por parte de sus usuarios: el teléfono es el ejemplo tradicional e Internet el más relevante hoy en día, aunque no hay que olvidar la importancia de las tarjetas de crédito para llevar a cabo acciones económicas, comerciales y financieras, ni la de otras tecnologías TIC a la hora de jugar y divertirse (infojuegos), trabajar (ordenadores) o desarrollar actividades creativas (multimedia). Las TIC proactivas han posibilitado nuevas formas de interrelación personal en el espacio electrónico (conversaciones telefónicas, correspondencia electrónica, acciones en red), así como la creación de objetos electrónicos nuevos (imágenes, sonidos, textos) y la emisión ulterior de los mismos, sea para el intercambio, la comercialización, el cumplimiento de una relación laboral (teletrabajo) o la simple expresión de lo que cada cual es en el espacio electrónico (páginas Web). Podrían aducirse otros muchos ejemplos, pero conviene insistir en que las TIC no sólo permiten el acceso a la información, sino también la acción a distancia y la emisión de contenidos de elaboración propia, sea en ámbitos públicos, privados o íntimos.

Esta distinción entre TICs proactivas y propasivas no debe ser entendida como una frontera tajante. Un teléfono, un ordenador conectado a Internet o un infojuego también pueden ser usados pasivamente. A la inversa, caben usos más activos o más pasivos de la radio y de la televisión. Lo importante es centrar el análisis del sistema TIC en la acción, más que en la información o la comunicación. Ésta es, al menos, nuestra perspectiva de estudio, bastante diferente de la que actualmente predomina. Si se piensa en el espacio electrónico como un lugar al que conviene acceder porque hay mucha información y contenidos de interés, como sucede en el paradigma dominante, sesgamos fuertemente nuestro análisis del espacio electrónico, sobre todo si estamos hablando de participación ciudadana. En lugar de concebir el espacio electrónico estáticamente, como un enorme depósito de información que ha sido puesta allí por los creadores de contenidos, concebimos el tercer entorno como un espacio para la acción a distancia y en red. Para ilustrar esa concepción, nada mejor que poner una serie de ejemplos canónicos. No sólo aludirán

${ }^{10}$ Es significativo que quien aparece en los medios adquiere prestigio social, independientemente de lo que haga. Por otra parte, los políticos, los empresarios e incluso las instituciones han de tener una imagen específica en los medios, así como una política informacional y comunicacional. 
a la participación en la vida pública. La vida privada es una componente muy importante en cualquier sociedad y la emergente sociedad de la información no es una excepción. Por ello, a la hora de analizar la participación ciudadana en el espacio electrónico, elegiremos algunos ejemplos correspondientes a ámbitos públicos, pero también otros que se refieren a ámbitos privados.

\section{El voto electrónico}

Cuando se habla de voto electrónico, normalmente se piensa en posibilitar la participación ciudadana en los procesos electorales de los países democráticos votando por medio de alguna TIC, y más concretamente por ordenador conectado a Internet. Veremos a continuación que, desde la perspectiva del sistema TIC, el elenco de posibilidades es mucho mayor. Asimismo mostraremos que, si aceptamos la hipótesis de los tres entornos, surge otra modalidad de votación electrónica, que nos parece mucho más importante cara al futuro: la elección de representantes de la ciudadanía para tomar decisiones sobre el desarrollo del espacio electrónico.

En primer lugar, conviene recordar que el voto electrónico ya se practica en redes telemáticas locales (como las comunidades virtuales ${ }^{11}$ ) y también en otros ámbitos sociales que conviene resaltar. En los últimos años, numerosos canales de televisión y operadoras de telefonía han creado sistemas para votar a favor de conjuntos musicales, concursantes en programas televisivos, etc. Ello implica una participación más activa por parte de los telespectadores. El instrumento para votar suele ser el teléfono, por el simple procedimiento de marcar un número u otro. No se trata de elegir a representantes políticos, sino, por ejemplo, de elegir al cantante que representará a un país en el Festival de Eurovisión, o de establecer el hit-parade del momento entre conjuntos musicales. La participación ciudadana suele ser significativa, sobre todo entre los jóvenes, lo cual no es de extrañar, dada la importancia de este tipo de entretenimientos en la vida social del tercer entorno. No hay garantías de que esos procedimientos vayan a ser limpios. Tampoco existe un censo electoral, secreto de voto o reglas básicas del tipo «una persona, un voto». Pero las votaciones electrónicas, como tales, ya existen. Significativamente, han sido promovidas por empresas privadas. Hay que subrayar que dichas votaciones se han convertido en una nueva vía de financiación para las productoras televisivas y musicales, puesto que votar tiene un costo económico, por pequeño que sea. La acción de votar por teléfono, siempre que sea masiva, supone un ingreso nada desdeñable para las compañías telefónicas, las cuales, consecuentemente, entran en los consejos de administración de las productoras musicales y de televisión. La

11 Veáse H. Rheingold, The virtual community, Reading, Addison-Wesley, 1993. 
identificación masiva con un personaje del tercer entorno, si se ve estimulada en forma de votación competitiva, da lugar a una forma de participación ciudadana que conviene tener presente, pese a que no se refiera a las elecciones políticas. En el fondo, esas votaciones muestran el estado actual del espacio electrónico, que está dominado por el mercado informacional, con una presencia muy exigua de lo que podría denominarse «poder infopolítico», o poder político en el espacio electrónico.

En segundo lugar, pensemos en algunos de los problemas que presenta el voto electrónico cuando éste se orienta a la elección de representantes políticos. El más importante tiene que ver con las capacidades de acción: saber votar. Saber votar por Internet no es nada sencillo, porque requiere un cierto grado de alfabetización digital. Hay que tener un ordenador, saberlo usar, entrar en la Web que haga el papel de urna electrónica, acreditar la identidad propia de modo que se preserve el secreto del voto, garantizar la confidencialidad de dicha acción, etc. Un porcentaje muy amplio de ciudadanos no tienen esa capacidad de votar electrónicamente, sea porque no disponen de los aparatos necesarios, sea porque no saben usarlos con el suficiente nivel de competencia. En el estadio actual de desarrollo de la sociedad de la información, la instauración de un sistema de participación directa de la ciudadanía, siendo tecnológicamente posible, sería elitista, puesto que sólo los poseedores de $e$-casas que tuvieran un cierto nivel de alfabetización digital podrían intervenir en los procesos de toma de decisiones. Por otra parte, existiría el riesgo de que quien votara efectivamente fuera un familiar o un amigo, puesto que suplantar la identidad en el espacio electrónico es muy fácil. La instauración de un sistema de voto electrónico para la toma democrática de decisiones o para la elección de representantes no sólo es un problema tecnológico, político, jurídico o económico, sino ante todo social y cultural. Lo importante es promover el desarrollo del espacio electrónico y de las capacidades de acción electrónica de la ciudadanía. Ello requiere formación de usuarios, gratuidad del voto, adecuación de los sistemas tecnológicos a los usuarios (en función de la edad y del nivel cultural), etc. Lo prudente es experimentar estas técnicas en redes locales, antes de pasar a implantarlas en elecciones generales. Como muestran algunas experiencias anteriores (México, Estados Unidos), el pucherazo electrónico es perfectamente posible.

Por otra parte, el sistema TIC ofrece otras alternativas para el voto electrónico, probablemente preferibles al voto por ordenador conectado a la red. Por ejemplo, la tarjeta de crédito puede valer como identificación del votante y el cajero automático más próximo puede convertirse en colegio electoral. Sin embargo, el avance de la televisión digital junto con una cierta informatización de la misma comporta un procedimiento más sencillo y, posiblemente, más universal, en el sentido de más accesible a la mayoría de la ciudadanía: votar con el mando a distancia. Bastaría con crear un canal electoral con clave de acceso secreta para cada persona, tecleable en el mando a distancia 
y con verificación de identidad por el procedimiento que se estableciera. El ciudadano elegiría a sus representantes por un procedimiento similar al de selección de un canal, acción ésta que la inmensa mayoría de las personas son capaces de llevar a cabo, precisamente porque la televisión es el artefacto más difundido socialmente del sistema TIC. Obviamente, esa aplicación del sistema TIC no sólo valdría para elegir representantes. También podría utilizarse para encuestas de opinión o, como muchos defienden, para instaurar formas más directas de participación ciudadana. La convergencia entre la televisión y los ordenadores permite transformar a la pequeña pantalla en un instrumento activo de participación, seleccionando entre opciones políticas y ciudadanas, en lugar de limitarse a elegir un canal comercial u otro. En resumen, en lugar de obsesionarse por desarrollar un sistema electoral en Internet y a través de la WWW, el sistema TIC ofrece otras posibilidades para el voto electrónico. Se trata de analizar cuál de los artefactos TIC es el mejor para votar en cada país y en cada caso. En el fondo, el sistema TIC ofrece varias vías para canalizar el voto y la opinión ciudadana.

En tercer lugar, el voto electrónico no sólo puede servir para elegir representantes para las instituciones del segundo entorno (Presidentes de Gobierno, parlamentarios, alcaldes, etc.), sino, sobre todo, para elegir a las personas que detenten el poder en el propio tercer entorno, es decir, a los Señores del Aire. Hoy por hoy, esta posibilidad parece muy utópica, porque implica la constitución de una pólis en el espacio electrónico (Telépolis) ${ }^{12}$, así como la instauración de un poder político transnacional que impere sobre el poder de los Señores del Aire, o cuando menos sirva de contrapeso. No existe ese tipo de poder en el tercer entorno, ni tiene visos de existir de manera inmediata, salvo en redes locales. En cualquier caso, éste sería el auténtico voto electrónico, porque supondría la participación de los ciudadanos a la hora de decidir el destino del nuevo espacio social, no de los espacios políticos vinculados a anteriores sistemas tecnológicos, como el sistema industrial y sus democracias representativas basadas en un tipo particular de empresa, los partidos políticos.

\section{Asociaciones y manifestaciones en el espacio electrónico}

Una de las formas típicas de participación ciudadana es la creación de asociaciones con fines específicos. Ello es perfectamente posible en el espacio electrónico, precisamente porque éste no sólo es global, sino también local. La red telemática local, integrada o no en Internet, es la forma canónica de construcción de un tejido social en el espacio electrónico. $\mathrm{O}$, si se prefiere, el número de redes locales y su nivel de actividad es un indicador del desarrollo de una sociedad civil de la información.

12 Véase Echeverría, 1994. 
Hay redes locales en las empresas y las instituciones, tanto para ofrecer información como, lo que es más importante, para desarrollar actividades conjuntamente mediante el recurso informático de los archivos compartidos. Actualmente, el ordenador conectado a una red es el principal recurso ofrecido por el sistema TIC para impulsar el asociacionismo en el tercer entorno, aunque tampoco hay que olvidar que las consolas de videojuegos pueden conectarse en red para desarrollar actividades lúdicas, como veremos en el apartado siguiente. Por tanto, las redes telemáticas son el instrumento TIC más adecuado para fomentar el asociacionismo, sin perjuicio de que la telefonía digital también genera interacciones grupales: los jóvenes han sabido usar esa herramienta TIC para crear lo que podríamos llamar cuadrillas electrónicas. Los chats, las listas de noticias y los reenvíos de mensajes a grupos que cada usuario crea en su libreta de direcciones son modalidades de vida civil en el tercer entorno, comparables a las tertulias, intercambios de noticias y al establecimiento de grupos de opinión. Un paso ulterior consiste en la creación de plataformas informáticas con acceso restringido, en las cuales se organizan debates o se ponen a disposición datos, imágenes, textos o melodías musicales. El caso Napster ha de ser recordado, puesto que aglutinó en muy poco tiempo a más de 60 millones de aficionados a la música que intercambiaban entre sí sus melodías favoritas, dando lugar a una especie de teleclub o telediscoteca musical. La posibilidad de crear copias de esos archivos musicales, típica del sistema TIC, supuso un tremendo impacto para las industrias discográficas, poniendo el problema de los derechos de autor en el centro de un debate social que todavía ahora está muy lejos de estar resuelto. En general, todas las tecnologías $C 2 C$ del sistema TIC fomentan la vida civil en el espacio electrónico y deben ser consideradas como instrumentos de participación ciudadana. Son tecnologías que desarrollan la vida privada en la sociedad de la información, puesto que generan $e$-clubs, que pueden ser abiertos o cerrados. Estos clubs electrónicos se ocupan de los temas más diversos: música, pornografía, religión, ciencia, política, juegos, ecología, tecnología, pacifismo, etc. Por supuesto, también los delincuentes pueden recurrir a estos instrumentos telemáticos para desarrollar sus actividades (fuga de capitales, lavado de dinero negro, comercio de info-armas, etc.). La sociedad de la información emergente genera nuevas formas de delito, del mismo modo que posibilita la creación de nuevos grupos que trabajan en red en pro de objetivos loables, como la defensa de los derechos de los ciudadanos en el espacio electrónico (Electronic Frontier Foundation, etc.). Las sectas de todo tipo han encontrado en Internet un excelente espacio para el desarrollo de sus actividades, al igual que las asociaciones de derechos civiles. Y los ejemplos podrían multiplicarse.

Lo importante es que el sistema TIC transforma las capacidades de acción individuales y grupales, y por ello genera nuevas modalidades de agrupación y asociación. Estamos ante formas innovadoras de participación 
ciudadana, que pueden ser positivas o negativas en función de los objetivos de la asociación, así como de sus modos de actuar. En todo caso, las TIC permiten participar en la vida civil del espacio electrónico, no sólo son instrumentos de búsqueda y adquisición de información. La vida infocivil puede estar orientada hacia lo bueno o hacia lo malo. No hay que pensar que la sociedad de la información no tendrá los problemas clásicos de cualquier sociedad. Lo importante es que esos problemas se plantean en otro espaciotiempo y que deben ser resueltos por vías muy diferentes a las usadas en las sociedades agrarias e industriales. De ello se deriva la necesidad de definir lo que es el derecho de asociación en el espacio electrónico, proscribiendo las asociaciones para delinquir, que pueden ser locales o transnacionales. El asociacionismo electrónico desborda fácilmente las fronteras de los países y los Estados, poniendo en cuestión uno de los principios básicos de la organización de las diversas formas de poder (legislativo, ejecutivo, judicial, económico, mediático, etc.): su territorialidad. Por mucho que los Parlamentos de los Estados-nación promulguen leyes sobre la protección de datos informáticos, nada impide a los Señores del Aire acceder a esos datos y luego operar con ellos, en su caso para comercializarlos. El asociacionismo electrónico depende estructuralmente de los Señores del Aire, que son quienes dominan las principales tecnologías TIC y dan cobijo en sus dominios a las asociaciones nacientes. Una compañía telefónica, una empresa que proporciona acceso, navegación o búsqueda por Internet, o una corporación que emite tarjetas de crédito, pueden acceder a los datos de los usuarios y conocer sus hábitos en el espacio electrónico, adquiriendo así un importante capital informacional, que luego tenderán a rentabilizar, salvo que lo impidan constricciones legales válidas para el conjunto del sistema TIC y del espacio electrónico. Es preciso promulgar leyes transnacionales en el espacio electrónico, así como crear los agentes que sean capaces de velar por su cumplimiento. Una de esas leyes versará sobre el derecho de libre asociación en el espacio electrónico, otra sobre el derecho de propiedad, otras sobre la libertad de empresa, de religión o de opinión. La sociedad de la información requiere un nuevo contrato social, convenientemente adaptado a la estructura del espacio electrónico.

Lo dicho anteriormente vale también para el derecho de manifestación en el espacio electrónico, que depende del derecho a la libertad de expresión en el tercer entorno. Al respecto, se producen choques culturales de gran interés, debido a que formas de expresión perfectamente aceptables en una determinada sociedad resultan lesivas u ofensivas en otras. Estando interconectadas las distintas sociedades y grupos entre sí, los límites de la libertad de expresión y manifestación han de ser redefinidos. En su breve historia, Internet ha servido como marco para nuevas formas de manifestación y de expresión, posibilitadas por el sistema TIC. Un ejemplo típico fue la telemanifestación global del 15 de febrero de 2003 contra la guerra en Irak. Aparte 
de los múltiples escritos de protesta firmados por millones de ciudadanos de diversos países, que fueron distribuidos a través de la red, ésta sirvió como vía de conexión entre los organizadores de múltiples manifestaciones locales que tuvieron lugar en dicha fecha. Como resultado, las televisiones de todo el mundo pudieron filmar la primera telemanifestación global de la historia, con una cabeza de manifestación que arrancó en Australia y a la que fueron incorporándose a lo largo del día y en función de los husos horarios de cada región nuevos manifestantes, cada uno de ellos caminando por las calles de ciudades que distaban entre sí cientos y miles de kilómetros. Los lemas, las consignas, las pancartas y las vestimentas de los manifestantes eran muy distintos según su cultura, lengua y motivación específica. Lo importante es que el sistema TIC permitió organizar esa telemanifestación, que luego pudo ser vista por todo el planeta. Este ejemplo muestra las enormes posibilidades que ofrece el sistema TIC para la participación ciudadana, en este caso ejerciendo el derecho a la libertad de expresión y de manifestación en un escenario transnacional y multicultural: el tercer entorno. Por otra parte, no hay que olvidar que, aparte de esas manifestaciones en las calles, la red había vehiculado otras muchas manifestaciones paralelas (escritos de protesta apoyados por ciudadanos de diversos países, imágenes alternativas, etc.), que también tuvieron lugar en el espacio electrónico. No faltaron los actos de sabotaje, tanto en algunas manifestaciones presenciales como en las manifestaciones virtuales. En conjunto, emergió una sociedad civil transnacional y transcultural, que supo aglutinarse en torno a un objetivo común.

Es previsible que este tipo de acciones cívicas continuarán, sea en el ámbito del movimiento antiglobalización, sea mediante acciones de movimientos ecologistas (Greenpeace siempre recurre al sistema TIC para sus acciones), sea en defensa de los derechos civiles individuales o colectivos. Más de una persona condenada a muerte en su país ha podido salvar la vida gracias a las acciones de esta opinión pública transnacional que va configurándose poco a poco. Como puede comprobarse, el sistema TIC no sólo modifica las capacidades de acción individual, también las colectivas.

La plataforma Linux es otro buen ejemplo de participación ciudadana, en este caso típicamente cooperativa. Cabe considerarla como un movimiento social alternativo al poder de los Señores del Aire, dado su enfrentamiento estratégico al poder de Microsoft. Su destino final es impredecible, pero su aparición y su progresiva influencia muestra que el sistema TIC y el espacio electrónico que de él se deriva puede ser organizado en base a principios diferentes. Como ya dijimos, el mercado informacional domina el espacio electrónico actual. La mera emergencia de un fuerte movimiento cooperativista en el sector de la informática muestra que caben diferentes modos de organización de dicho mercado informacional. Y no hay que olvidar que el problema principal consiste en definir el contrato $e$-social, es decir, en repensar la declaración de derechos humanos de 1948 para el espacio elec- 
trónico. Sólo a partir de esa $e$-declaración cabrá hablar de una sociedad de la información en el pleno sentido de la palabra.

Comprobamos así la importancia que tienen los marcos conceptuales a la hora de reflexionar sobre el impacto social de las tecnologías de la información y la comunicación. Si aceptamos la hipótesis del sistema TIC y su consecuencia ulterior (emergencia del espacio electrónico), las formas tradicionales de participación ciudadana (asociación, manifestación, libertad de expresión) cambian profundamente de sentido. Los problemas siguen siendo los mismos, pero se plantean en un nuevo espacio social y por ello han de ser abordados desde marcos conceptuales específicos.

\section{El deporte en el tercer entorno}

La distinción que establecimos en el segundo apartado entre tecnologías TIC proactivas y propasivas quedará más clara si consideramos brevemente el desarrollo de las actividades deportivas en el espacio electrónico durante los últimos años. Participar en las actividades lúdicas y deportivas siempre ha sido uno de los rasgos distintivos de la vida civil, que requiere actividad e iniciativa por parte de los participantes. Se trata ahora de ver de qué manera se desarrolla el deporte en el espacio electrónico, o si se prefiere, qué aportaciones hace el sistema TIC a la participación deportiva y lúdica de las personas.

Uno de los grandes éxitos de la radio y la televisión han sido las retransmisiones deportivas. Las Olimpiadas, los campeonatos mundiales de fútbol, la Superbowl, la liga ACB de Baloncesto, la Copa Davis de tenis y otros muchos espectáculos deportivos han supuesto grandes éxitos de audiencia para los medios de comunicación radiotelevisivos. Independientemente de que cada cultura prefiera un deporte u otro, lo cierto es que todos y cada uno de los deportes de amplio seguimiento popular se han ido adaptando al nuevo espacio social. Baste pensar en el éxito de las retransmisiones ciclistas, de tenis, de baloncesto, de motociclismo, de fórmula 1 o de fútbol para hacernos idea del enorme impacto del sistema TIC sobre los deportes populares, al permitir que grandes masas de espectadores puedan ver o escuchar esas competiciones a través de dos de las interfaces del espacio electrónico, la radio y la televisión. Antiguamente había que ir al estadio, leer la prensa o escuchar los comentarios de quienes habían asistido al acontecimiento. La difusión masiva de estas tecnologías ha incrementado las capacidades de las personas, permitiéndoles contemplar o escuchar lo que ocurre en tales eventos deportivos. En este caso se trata de tecnologías que promueven el espectáculo, más que la intervención activa, pero ello no impide participar mentalmente en la competición, en la medida en que uno se identifica con unos colores o con unos deportistas. Aunque con un alto grado de pasividad, se trata de una forma de participación que ha adquirido enorme relevancia 
social desde que emergió el tercer entorno, hasta el punto de haberse convertido en un fenómeno de masas que canaliza muchas tensiones sociales. Ésta es la razón principal del éxito del teledeporte, entendiendo por tal la transmisión a través de redes TIC de lo que ocurre en los campeonatos o competiciones deportivas.

Si pasamos ahora a las tecnologías más proactivas, la noción misma de deporte se transforma. Los espectáculos que hemos mencionado no son deportes del tercer entorno, sino competiciones típicas de la civilización industrial. Los clubes de fútbol, baloncesto, rugby, béisbol, ciclismo, etc., son industrias deportivas, que funcionan gracias a un sistema industrial de organización de dichas actividades. Independientemente del status jurídico que tengan, tanto por el modelo organizativo como por la profesionalización de jugadores y directivos, las sociedades deportivas de incidencia masiva son típicas de la civilización industrial. Por tanto, estamos ante deportes del segundo entorno vistos desde el tercer entorno. La presencia de los micrófonos y de las cámaras de televisión transforma esas actividades deportivas, ante todo porque las convierte en telespectáculos de masas. La información deportiva es un sector importante de los medios impresos y audiovisuales, pero, como tales deportes, no cabe decir que sean específicos de la sociedad informacional. Otro tanto cabe decir de los juegos de mesa o de cartas, que también se adaptan al espacio electrónico, pero manteniendo sus marcas originarias.

Lo que podemos denominar propiamente $e$-deporte surge con los videojuegos y las simulaciones informáticas. Son infojuegos, es decir, deportes de la información y el conocimiento. En ellos no juegan las mentes moviendo cuerpos físicos, como ocurría en el primer y el segundo entorno, sino mediante flujos de bits. Es posible simular los juegos físicos, como muchos videojuegos hacen, pero la especificidad del deporte electrónico consiste en ser puramente mental e informacional. Como en los dibujos animados, se simula el movimiento en pantalla, adecuándolo a las condiciones perceptivas de los seres humanos. Pero en realidad sólo hay flujos de bits, transformaciones informáticas previamente programadas. En las retransmisiones televisivas se tiene la sensación de que uno está contemplando algo real, entendiendo por real lo que ocurre en una ciudad industrializada. En cambio, los videojuegos se desarrollan en mundos virtuales, que pueden simular o no escenarios habituales del primer o segundo entorno. Lo más habitual es que generen sus propios escenarios, cuyos diseños sólo son posibles con herramientas informáticas. Por ello son juegos y deportes del tercer entorno, no representaciones de juegos que acontecen en el espacio físico o urbano.

La diferencia es cualitativa, pero no impide la participación de los seres humanos en la nueva modalidad de juego y deporte mental. De hecho, las videoconsolas son uno de los artefactos del sistema TIC que mayor aceptación tienen entre los niños y los jóvenes. Su cuota de mercado actual es supe- 
rior a la del cine, y sigue creciendo. El jugador se identifica con un infoobjeto y participa en aventuras, competiciones y, en algunos pocos casos, en juegos cooperativos. La contienda típica se establece entre la mente humana y el software de la máquina, con diversos niveles de dificultad. No se aprende a mover el cuerpo, pero sí se adquieren nuevas capacidades de acción en el espacio electrónico, así como habilidades y destrezas específicas. Estando los adultos habituados a los deportes de la civilización industrial, su acceso al nuevo espacio lúdico presenta grandes dificultades. De hecho, existe una brecha generacional muy clara en todo lo que atañe a los infojuegos. Los niños que se han constituido como personas con el tercer entorno como paisaje diferenciado dentro de su Lebenswelt aprenden a intervenir en dicho espacio lúdico. Salvo excepciones, los adultos se sienten inseguros y extraños a él. Las diferencias estructurales entre el tercer entorno y los otros dos se manifiestan con toda nitidez en el caso de los infojuegos. El jugador interviene una y otra vez en el campo de juego, delimitado por la pantalla, pero lo hace para operar con un nuevo tipo de objeto, los infoobjetos, que son cualitativamente diferentes de los objetos de juego tradicionales (muñecas, balones, fichas, etc.). La adicción a los nuevos objetos lúdicos es tan grande como la que los niños y niñas han mostrado tradicionalmente por sus juegos favoritos. Baste pensar en las horas que un niño o una niña puede estar jugando compulsivamente con una muñeca o con un balón. La diferencia estriba en que, en este caso, no se juega con objetos materiales, sino informacionales. Los instrumentos para jugar también son completamente distintos. Sin embargo, la pasión participativa no disminuye, sino que es tan intensa (o más) como la que los jóvenes han mostrado siempre por los juguetes industriales.

El mundo de los infojuegos merecería un estudio en profundidad, por ser una de las grandes novedades del sistema TIC. Se insiste mucho en la relevancia de la telefonía móvil, de la televisión, de Internet o de las redes de cajeros automáticos. Sin embargo, igual de importante, si no más, es la tecnología de infojuegos, que se integra bien en los demás artefactos TIC. En los últimos años, los teléfonos móviles, los canales de televisión $\mathrm{y}$, por supuesto, los ordenadores ofrecen cada vez más juegos electrónicos. Si se hiciera un estudio empírico del tiempo que las personas dedican a jugar en el espacio electrónico, se comprobaría probablemente que crece de manera constante, si no exponencialmente. En este caso no se trata de acceder a la información ni de comunicarse, sino de jugar, acción típica de todas las culturas humanas. La emergencia de una nueva modalidad de juego y de deporte, estrictamente mental, es un argumento más a favor de la hipótesis de que estamos ante un nuevo espacio social, no simplemente ante un conjunto de nuevos artefactos tecnológicos.

El desarrollo de la sociedad de la información requiere la organización del sector lúdico de dicha sociedad, tarea ésta a la que se la prestado muy poca atención. Es posible organizar, por ejemplo, campeonatos escolares 
con algunos videojuegos, del mismo modo que se organizan campeonatos escolares de fútbol, de atletismo o de ajedrez. Al jugar en el espacio electrónico los niños y niñas adquieren nuevas capacidades de acción, que pueden parecer irrelevantes desde la perspectiva de las sociedades agrarias e industriales, pero que serán importantísimas para su futuro como $e$-ciudadanos. Dominar las especificidades del espacio electrónico se logra con la práctica, y no hay práctica mejor que el juego para conocer el entorno donde uno actúa, en este caso el tercer entorno. También los adultos deberían aprender la nueva modalidad de juego. Algunos de ellos ya lo hacen, por ejemplo los pilotos de los bombarderos, en cuya formación militar se incluye el dominio de estos nuevos instrumentos lúdicos. La precisión a la hora de localizar un objeto concreto, la rapidez al actuar, la capacidad de responder a un objeto que irrumpe en pantalla, la armonización entre mente y pantalla, la identificación con infoobjetos, etc., son habilidades imprescindibles para la infoguerra actual. Otro tanto cabría decir de los controladores aéreos, de los televigilantes y de los diversos oficios que, cada vez más numerosos, dependen estrictamente del sistema TIC para ser practicados competentemente.

Al igual que los deportes físicos, los $e$-deportes tienen riesgos, en este caso riesgos mentales. Todavía no ha surgido una medicina $e$-deportiva, pero la veremos emerger a lo largo del siglo XXI. Será una medicina mental, más que corporal. Todo ello sin perjuicio de la aparición de nuevas enfermedades físicas. Como cualquier forma social, la sociedad de la información generará sus propias modalidades de enfermedad, previsiblemente mentales. Cuando se habla alegremente de la sociedad del conocimiento, no hay que olvidar que también existen las enfermedades del conocimiento, o $e$-enfermedades. Impulsar el deporte electrónico es preciso, pero prestando mucha atención a los riesgos que comporta. Los planes de $e$-educación deberían contener apartados específicos sobre esta modalidad de acción educativa. Hoy por hoy, los niños y las niñas son autodidactas en los juegos electrónicos e informacionales. Atender a esta forma de participación activa en el espacio electrónico es, a nuestro modo de ver, una de las prioridades de las políticas que tiendan a impulsar la enseñanza apoyada en las tecnologías de información y comunicación.

En resumen, el tercer entorno reproduce muchos de los deportes y juegos tradicionales, normalmente con gran éxito. Pero, además, el sistema TIC ha generado nuevas formas de juego y de competición deportiva, a las que hay que prestar gran atención. Participar en estas actividades forma parte de la preparación de una persona para la sociedad de la información. Suele ser una participación en ámbitos privados, mas no por ello menos importante para su formación como persona competente en el manejo del sistema TIC. 


\section{Conclusión}

Podríamos aportar otros muchos ejemplos, pero los tres anteriores pueden dar idea de la amplitud del desafío planteado por el sistema TIC a las diversas formas de participación ciudadana que cabría analizar. A pesar de las grandes diferencias entre los ejemplos aportados, de todos ellos se desprende una conclusión común: para participar en la vida infosocial es preciso adentrarse en un nuevo espacio-tiempo, cuya estructura difiere radicalmente de los espacios naturales y urbanos, donde tradicionalmente se ha hablado de participación de la ciudadanía en la vida civil.

En conjunto, el desafío consiste en organizar, civilizar, humanizar y, en su caso, democratizar el nuevo espacio social. El sistema TIC ofrece herramientas para ello. Y si no las hay todavía, habrá que innovar en esa dirección. Ya hemos indicado la conveniencia de introducir regulaciones para desarrollar las diversas modalidades de participación ciudadana en el espacio electrónico.

Lo importante es tener en cuenta que, de llegar a haber $e$-ciudadanos (por el momento somos consumidores de información, clientes de los Señores del Aire y usuarios de los artefactos del sistema TIC), dicha ciudadanía habrá de incluir a la multitud de usuarios del sistema TIC. Ello implica un tipo de ciudadanía muy diferente a la que se ha conocido en las sociedades agrarias y en las sociedades industriales regidas por los Estados-nación. El tránsito de la ciudadanía urbana e industrial, hoy en día dominante, a la infociudadanía, exige promover las tecnologías proactivas antes mencionadas. Pero, además, requiere reflexionar a fondo sobre las componentes básicas de una sociedad civilizada, y más concretamente de una sociedad democrática.

Dicho en términos filosóficos clásicos: si pretendemos democratizar el espacio electrónico hemos de tener en cuenta que no sólo cambia el kratós o poder, porque el sistema TIC genera nuevas capacidades de acción, sino también el démos. No se es $e$-ciudadano por nacimiento ni por residencia en un lugar, sino por participación en las diversas actividades que se desarrollan en el espacio electrónico. Por tanto, el démos de la sociedad de la información incluye a personas de diversas culturas, que sólo participan del nuevo espacio social en la medida en que utilizan el sistema TIC. La construcción de Telépolis en el espacio electrónico ha de hacerse con ayuda de dicho sistema tecnológico, mas también teniendo en cuenta la singularidad del nuevo démos informacional. En la medida en que los actuales usuarios, consumidores y clientes de los servicios TIC se piensen a sí mismos como ciudadanos de un nuevo espacio social, donde tienen derechos y responsabilidades, se abrirán nuevas vías de participación ciudadana. De lo contrario, el sistema TIC será un simple instrumento para administrar mejor el poder económico, político y militar que impera en las sociedades industrializadas. 


\section{BIBLIOGRAFÍA}

AgAZZI, E. (1998): La technoscience et l'identité de l'homme contemporain, Friburgo, Ed, Universitaires Fribourg, Suiza.

Álvarez, J. F. (2001): «Capacidades potenciales y valores en la tecnología: elementos para una axionomía de la tecnología», en LóPEz CEREzo y SÁNCHEz RoN (eds.) (2001), pp. 231-242.

ÁlvareZ, J. R. (2001): «La ciencia y los valores: la interpretación de la actividad científica», en M. I. Lafuente (ed.) (2002), pp.17-33.

Buchwald, J. Z. (ed.) (1995): Scientific Practice, University of Chicago Press.

CAstells, M. (1996-1998): La Era de la Información, 3 vols, Madrid, Alianza.

ECHEVERRÍA, J. (1998a): «Teletecnologías, espacios de interacción y valores», Teorema, núm. II, p. 5.

- (1999b): Los Señores del Aire. Telépolis y el Tercer Entorno, Barcelona, Destino.

- (2001): «Tecnociencia y sistemas de valores», en LóPEZ CEREzo y SÁNCHEz RoN (eds.) (2001), pp. 221-230.

- (2002): Ciencia y valores, Barcelona, Destino.

- (2003): La revolución tecnocientífica, Madrid-México D. F., FCE.

Galison, P., y Hevly, B. (eds.) (1992): Big Science: the Growth of Large-Scale Research, Stanford, Stanford Univ. Press.

González García, M. I.; López Cerezo, J. A. y Luján López, J. L. (1996): Ciencia, tecnología y sociedad. Una introducción al estudio social de la ciencia y la tecnología, Madrid, Tecnos, 1996.

GonzÁlez García; M. I., LóPez Cerezo, J. A. y LujÁn LóPez, J. L. (eds.) (1997): Ciencia, Tecnología y Sociedad, Barcelona, Ariel.

Ibarra, A., y López Cerezo, J. A. (eds.) (2001): Desafíos y tensiones en Ciencia, Tecnología y Sociedad, Madrid, Biblioteca Nueva-OEI.

KuHn, T. S. (1975): La estructura de las revoluciones científicas, México, FCE.

- (1982): La tensión esencial, México, FCE.

- (1989): ¿Qué son las revoluciones científicas? y otros ensayos, Barcelona, Paidós.

LAFUENTE, M. I. (ed.) (2001): Los valores de la ciencia y la cultura, León, Universidad de León.

LAUDAn, L. (1984): Science and Values, Berkeley, University of California Press.

Longino, H. E. (1990): Science as Social Knowledge. Values and Objectivity in Scientific Inquiry, Princeton, Princeton University Press.

López Cerezo, J. A.; Méndez Sanz, J. A., y TodT, O. (1998): «Participación Pública en Política Tecnológica», Arbor, CLIX, núm. 627, pp. 279-308.

López Cerezo, J. A., y SÁnchez Ron, J. M. (eds.) (2001): Ciencia, Tecnología, Sociedad y Cultura, Madrid, Biblioteca Nueva-OEI.

Luján, J. L. y López Cerezo, J. A. (2000): Ciencia y política del riesgo, Madrid, Alianza.

Olive, L. (2000): El bien, el mal y la razón, México, Paidós.

Pickering, A. (ed.) (1992): Science as Practice and Culture, Chicago y Londres, University of Chicago Press.

PiCKering, A. (1995): The Mangle of Practice, University of Chicago Press.

Quintanilla, M. A. (1989): Tecnología. Un Enfoque Filosófico. Madrid, Fundesco.

Rouse, J. (1987): Knowledge and Power. Toward a Political Philosophy of Science, Ithaca y Londres, Cornell Univ. Press. 
- (1996): Engaging Science. How to Understand its Practices Philosophically, Ithaca y Londres, Cornell.

SÁnchez Ron, J. M. (1992): El poder de la ciencia, Madrid, Alianza.

- (1998): Falsos mitos: ciencia versus tecnología, Madrid, Fundación Repsol.

SEN, A. (1997): Bienestar, justicia y mercado, Barcelona, Paidós.

Solla PrICE, D. della (1973): Hacia una ciencia de la ciencia, Barcelona, Ariel. 